\title{
Nuno Ramos e a obra visual: da sintaxe barroca à alegoria dadaísta nos Quadros sem títulos
}

\section{CHRISTIANE DE FARIA PEREIRA ARCURI}

\section{Resumo}

Discorremos sobre a obra visual de Nuno Ramos (1960): da sintaxe barroca à alegoria dadaísta nos Quadros sem títulos (entre 1987 e 2008). Averiguamos - no que concerne ao aspecto plástico-conceitual -, como as características estéticas, por vezes similares às do período do Barroco (séculos XVII-XVIII), assim como as particularidades provenientes da linguagem estilística recorrente à técnica do processo Merz dadaísta (século XX), ressoam nos Quadros sem títulos.

Palavras-chave: Artes Visuais, antiobjeto, contemporaneidade Relacionamos a (re)apresentação estética do objeto visual na constituição do antiobjeto pautado à efemeridade e ao desperdício cotidiano da contemporaneidade. 


\section{Nuno Ramos and the visual work: from the baroque syntax to the dadaist allegory in Tables without titles}

\begin{abstract}
We discuss the visual work of Nuno Ramos (1960): from the baroque syntax to the dadaist allegory in Tables without titles (between 1987 and 2008). We have noticed -with respect to the plastic-conceptual aspect -howthe aesthetic features, sometimes similar to the Baroque period (XVII-XVIII centuries), as well as the particularities originatedfrom the stylistic language recurrent inthe technique of the dadaist Merz process (XX century),both echo in Tables without titles. I establish a relation between theaesthetic (re)presentation of the visual object in the constitution of the antiobject with the ephemerality and the daily waste of contemporaneity.
\end{abstract}

Keywords:

Visual Arts, antiobject, contemporaneity 


\section{Nuno Ramos y la obra visual: de la sintaxis barroca a la alegoría dadaísta en los Cuadros sin títulos}

CHRISTIANE DE FARIA PEREIRA ARCURI

\section{Resumen}

Hablaremos en este texto sobre la obra visual de Nuno Ramos (196o): de la sintaxis barroca a la alegoría dadaísta en los Cuadros sin títulos (entre 1987 y 2008). Indagamos -en lo que concierne al aspecto plástico-conceptualcómo las características estéticas, algunas veces similares a las del periodo Barroco (siglos XVII-XVIII), así como las particularidades provenientes del lenguaje estilístico derivado de la técnica del proceso Merz dadaísta (siglo XX), resuenan, ambas, en los Cuadros sin títulos. Relacionamos la

Palabras clave: Artes Visuales, antiobjeto, contemporaneidad (re)presentación estética del objeto visual en la constitución del antiobjeto pautado en lo efímero y en el desperdicio cotidiano de la contemporaneidad. 


\section{Introdução}

Nesse estudo abordamos a obra visual de Nuno Ramos (1960), mais precisamente, os Quadros sem títulos, que o artista produz ininterruptamente desde o ano de 1987 até 2008.

Nuno Ramos dedica-se às Artes Visuais desde fins da década de oitenta. Suas experimentações artísticas são aplicadas em muitos suportes, tais como Pintura, Escultura, Instalação, Intervenções Urbanas, Ilustração de livros, Vídeo e Cinema.

Suas obras visuais mais conhecidas e mais representativas no panorama das Artes Visuais da contemporaneidade são as seguintes: Mácula (1994); Craca (1995); Para Goeldi (1996); Manorá Branco (1997); Minuano (200o); Morte das Casas (2004); Que (2004); Vai Vai (2006); Mar Morto (2008); Bandeira Branca (2010); Globo da morte de tudo (2012); Hora da razão (2014).

Em se tratando dos Quadros sem títulos constatamos que algumas questões estilísticas e conceituais tornam-se relevantes no percurso da produção do artista, a saber: i) uma possível recorrência, na obra visual, de algumas características estéticas reconhecidamente à época do Barroco (séculos XVII e XVIII), apesar das diferenças de seus meios de expressão entre a obra de Nuno Ramos e o período Barroco; ii) uma reflexão resultante das prováveis conexões conceitualmente alegóricas na obra visual; iii) e a questão que surge a partir da percepção de traços similares com a técnica do processo Merz dadaísta (século XX) como uma linguagem estilística recorrente nesses Quadros sem títulos produzidos pelo artista.

Nesse sentido, surge a necessidade de compreendermos as especificidades estéticas e conceituais referendadas nesse estudo, tanto pelo período entendido como Barroco como pelo movimento artístico denominado Dadaísmo, no que concerne ao estado de espírito e às soluções estilísticas próprias desses recor- 
tes históricos, para que a obra visual de Nuno Ramos, a começar pelos Quadros sem títulos, seja entendida como uma referência importante na produção da arte da contemporaneidade.

\section{O conceito benjaminiano de alegoria barroca}

Quando surgiu no século XVIII, o conceito aplicado ao Barroco ainda dizia respeito, conforme Hauser (1982, p. 556), "àqueles fenômenos de arte que se sentiam, de acordo com a estética classicista dominante, como extravagantes, confusos e bizarros". A arte à época do Barroco não tinha um caráter estilístico uniforme, podendo ser considerada naturalista e classicista, analítica e sintética. A arte barroca, sujeita às preocupações da Contrarreforma, "tem como objetivo essencial provocar o fervor das multidões, criar a surpresa, o encantamento, o deslumbramento [através da] fusão dos elementos, [...] as técnicas combinam-se e fundem-se" (UPJOHN, 1977, p. 10).

O autor Wölfflin (2000, p. 558) apresenta uma concepção qualitativa do Barroco ao enumerar conceitos opostos às características da Renascença: a dissolução da forma plástica e linear em lugar de qualquer elemento que pareça em constante movimento; a obliteração de limites e contornos para sugerir pontos de fuga de uma visão infinita ocasionada por primeiros planos maiores do que o tamanho natural, com figuras em relevo trazidas para o alcance do observador e de uma súbita redução de proporções nos motivos do fundo; a transformação do espaço estático num devir de mobilidade intrínseca, como num processo em constante formação com elementos incompletos e aparentemente desconexos, como se continuassem além daquele plano, além deles mesmos.

De acordo com a concepção de Wölfflin (2000) sobre as categorias do Barroco, no que diz respeito à sua natureza pictórica, tanto a disposição assimétrica dos seus elementos quanto a ausência de unidade, e sua consequente desorganização espacial e estética, contribuem para a dissolução da forma plástica linear em algo móvel e mutável, com destaque para diferentes pontos de luz - as obras barrocas são consideradas, no século XVIII, desproporcionais, extravagantes e confusas.

Nos Quadros sem títulos do artista Nuno Ramos, a grande quantidade e diversidade de elementos trazem a instabilidade entre as formas e os volumes, numa superfície propositalmente sobrecarregada e amparada num desequilíbrio visual; pontos de fuga e de luz dinamizam a superfície pictórica e matérica, o que resulta numa tensão entre as formas originais dos objetos 
acoplados à tela e o aspecto de estranhamento que causam - o que Tassinari chama de "regeneração" ou "encantamento", uma vez que "um pedaço qualquer de algo ganha um novo mundo onde é reinventado" (TASSINARI apud RAMOS, 1997, p. 12).

Os primeiros Quadros sem títulos de Nuno Ramos produzidos até o início da década de 1990 (Figura 1) já apresentam, pela movimentação das massas, o hibridismo causado pelas substâncias e o dinamismo das cores que aperfeiçoam o "dramatizar [d]o informe como um labirinto de asperezas e descontinuidades", favorecendo "no dinamismo dos contrastes e no grotesco das transições e fluxos [um] esforço de traduzir o um no outro" (DIAS apud ALENCAR, 2011, p. 29).

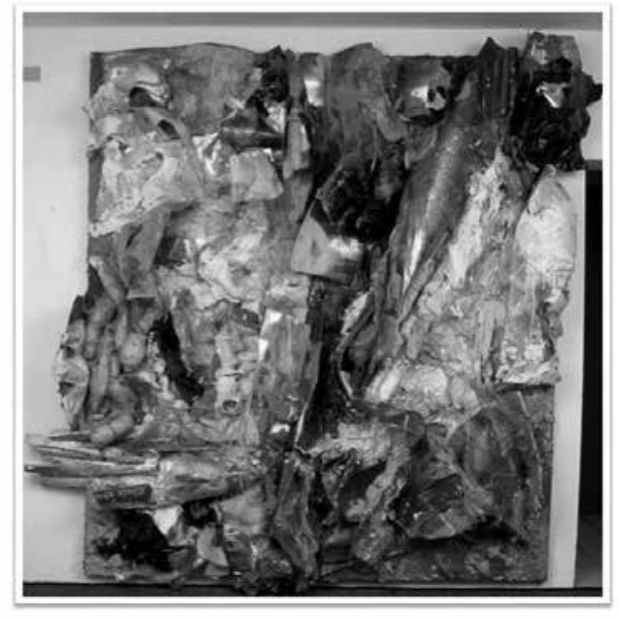

O crítico de artes visuais Mammi (1997, p. 20o), especializado na obra de Nuno Ramos, diz que este é um artista da crise das vanguardas. E o artista demonstra, a partir da fluidez dos sentidos provocados pelos materiais, desenvolver uma espécie de virtuosismo nessa aparente perda de controle estético e conceitual. A autora e colecionadora de arte Klabin, quando se refere aos Quadros sem títulos (mesmo os dos anos dois mil - Figura 2), os coloca como uma marca visual e referência singular da produção artística da contemporaneidade: "Esta conjugação de elementos difusos forma uma espécie de poema sinfônico contemporâneo de harmonias dissonantes com rápidas alterações de ritmos, sem qualquer centro tonal ou estruturas temáticas" (KLABIN apud RAMOS, 1999, p. 6).

A questão que se torna pertinente para o estudo desses Quadros sem títulos, de Nuno Ramos, repousa justamente
Figura 1

Nuno Ramos, Sem título, tecidos, folhas, plásticos, tintas, metais e resina sobre madeira, $260 \mathrm{~cm} \times 200 \mathrm{~cm}, 1990$. Disponível em: <www.nunoramos.com.br>.

Acesso em: 13 dez. 2013 
Figura 2

Nuno Ramos, Sem título, espelho, vidro, acrílico, folha de ouro, metal, tecidos, algodão, folhas secas, plásticos, esmalte sintético, óleo de linhaça, terebintina, parafina, vaselina, breu, resina sobre madeira, $200 \mathrm{~cm} \times 320 \mathrm{~cm}$ $x 130 \mathrm{~cm}, 1993-98$. Coleção Charles Cosac. Fonte: RAMOS, 1999, p. 78-79

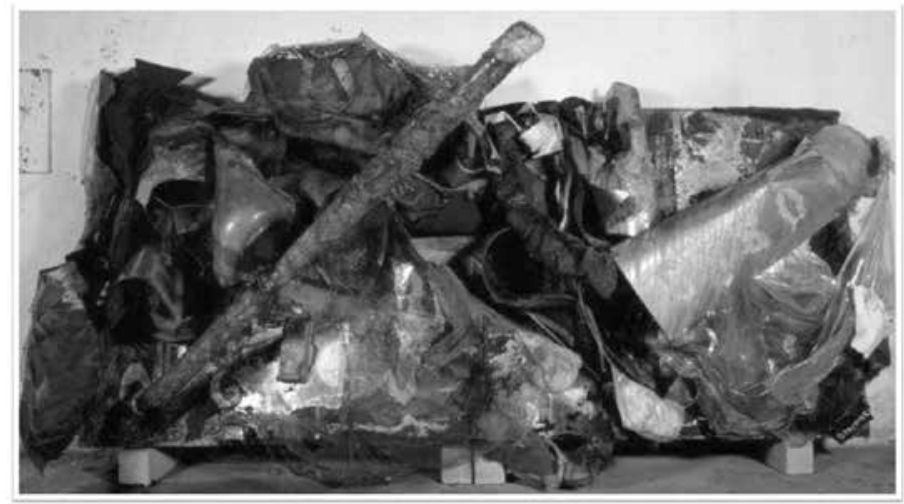

nesse sentido: amparado na sintaxe visual barroca, o artista, ao atribuir novo significado às coisas banais do cotidiano atual, e apropriando-se conceitualmente dessas coisas ao tornar o encantamento possível (somente possível em obras de arte), coloca seus Quadros sem títulos (as pinturas) como representantes de um processo de alegorização.

Em busca de justificar como a segunda questão aqui posta sobre a obra visual de Nuno Ramos pode ser resultante das conexões conceitualmente alegóricas, recorremos a Walter Benjamin (1892-1942) e às suas contribuições ao estudo pós-moderno da alegoria. Sua concepção barroca da história e a mediação entre sua origem e sua estrutura resultante numa linguagem alegórica desenvolvem- se em dois momentos: nesse estudo nos detemos na relação que o autor estabelece aos contextos do Barroco, no livro Origem do drama barroco alemão (1984).

$\mathrm{Na}$ apresentação desse livro de Benjamin, Rouanet escolhe três abordagens para preparar uma leitura sistemática: uma teoria do conhecimento, uma teoria do drama barroco e uma teoria do alegórico. Ao iniciar pelas interpretações do Barroco (o drama barroco - a tragédia), esclarece de maneira didática as reflexões benjaminianas acerca das ideias e das coisas, acerca do nome e da palavra, acerca da origem e da gênese e sobre a filosofia e o sistema. Além disso, para que possamos compreender a teoria do alegórico, torna-se importante revermos a teoria do conhecimento e, sobretudo, da linguagem. No ensaio, o autor trata, na primeira parte, da crítica ou da teoria do conhecimento - uma investigação filosófica sobre a questão da representação ligada à ordem das ideias.

Considerando a teoria das ideias em relação à estética, Benjamin destaca o drama barroco do século XVII como uma ideia que pode ser representada através do conceito (a mediação entre o particular e o universal) dos seus elementos 
mais característicos. As expressões exageradas e irregulares, percebidas nos elementos do drama barroco, enfatizam ideias extremadas em obras representativas da época - a representação do drama barroco ativa o percurso para a investigação filosófica das ideias e das coisas à época.

Para Gagnebin (apud PRESSLER, 2006, p. 173), um ponto central do livro sobre o Barroco alemão é a discussão sobre a alegoria e sua reabilitação, na perspectiva da sua significação como alegoria moderna, a qual revolucionou a crítica literária - o drama barroco traz a busca da origem da alegoria ao mesmo tempo em que é a alegoria da origem. Gagnebin (p. 178) complementa essa teoria introduzida por Rouanet dizendo que a ideia é apresentada através da singularidade do seu conteúdo imanente à própria obra. Nesse sentido, Benjamin situa-se além do nominalismo e distante do realismo. Da mesma forma, o realismo julga a obra através das regras definidas e aplicadas. Em ambas as abordagens teóricas, a particularidade de cada obra desaparece - o próprio objeto se perde. Benjamin quer esmiuçar; ele quer penetrar e mergulhar na obra, por isso insiste num certo "platonismo" que define como um "objetivismo radical" (BENJAMIN, 1984, p. 15) para "salvar os fenômenos" e o aprofundamento da teorização da forma.

As ideias, portanto, estão localizadas na linguagem, na ordem do Nome. O Nome transforma-se na palavra que se torna mero fragmento semântico, coisa entre coisas, como uma dialética que vai perdendo a capacidade de nomeação. A teoria linguística do Barroco representa essa tensão entre nome e palavra quando opõe a linguagem oral (como expressão livre e onomatopaica que nomeia as coisas com o seu nome correspondente) à linguagem escrita que deveria atribuir significações às coisas. O drama barroco, na prática, é o fenômeno e, como Nome, é a ideia. A função comunicativa da linguagem é uma decorrência da perda de identidade entre a palavra-sentido e a coisa-sentido; a linguagem desenvolve sua dimensão simbólica, tornando-se instrumento de comunicação, após perder a intenção de nomear. A palavra deixa de ser nome e, tornando-se signo, se refere à própria coisa enquanto seu significado. Na teoria da linguagem barroca pelo viés benjaminiano, é necessário que três fatores estabeleçam uma simbiose entre o seu significado, ou melhor, que de um lado estejam as coisas, de outro, as palavras e, intervindo como terceiro elemento ou fator, uma pessoa que as relacione entre si, o intérprete.

$\mathrm{Na}$ história, à época barroca, as ideias são intemporais, seguem em direção ao novo, uma vez que estabelecem relação 
com a sua pré e pós-história. A forma característica que se origina, contudo, é a da restauração e reprodução (refere-se ao passado) ao mesmo tempo em que é incompleta e acabada (é predisposta para o futuro). O objeto que tem sua origem na história desprende-se do vira ser; o termo origem não indica o vira ser daquilo que se origina, e sim algo que emerge posteriormente ao vira ser e à extinção. $\mathrm{O}$ historiador dialético deve favorecer o desprendimento do objeto histórico do fluxo da história contínua - deve contribuir para que o objeto seja compreendido como fragmento da história. Na perspectiva estrutural, os encadeamentos cronológicos não contam tanto quanto as afinidades internas, que só distanciam aparentemente duas épocas (a pré e a pós-história em relação ao período barroco).

Para que a interpretação do conceito benjaminiano de alegoria possa ser entendida, Rouanet parte do contexto etimológico do termo (falar alegoricamente significa dizer uma coisa para significar outra) e da recusa de Benjamin pelos preceitos teóricos anteriores, como os greco-latinos, que entendiam a alegoria como uma forma essencialmente antiartística e uma ideia abstrata. E Rouanet instaura uma questão: "A alegoria entendida como figura pela qual falando de uma coisa pode significar outra, qual é a outra coisa, então, significada pela alegoria barroca?". É próprio do Barroco que "cada pessoa, cada relação pode significar qualquer outra" (ROAUNET apud BENJAMIN, 1984, p. 196). Gagnebin (apud PRESSLER, 2006, p. 180) complementa dizendo que a resposta à questão de Rouanet não está no campo fenomenológico, mas sim na essência, na metafísica.

De acordo com a Enciclopédia e dicionário ilustrado (1997, p. 10), alegoria tem a seguinte definição: "Simbolismo concreto que abrange o conjunto de toda uma narrativa ou quadro, de maneira que cada elemento do símbolo corresponda a um elemento significado ou simbolizado", isto é, além de servir como figura de linguagem para textos, bastante comum em fábulas e parábolas, cabe também a obras de arte. Já conforme o Dicionário de termos literários (1997, p. 14), a própria construção etimológica da palavra alegoria, que vem do grego allegoría, indica um "discurso acerca de uma coisa para fazer compreender outra"; dizer alguma coisa diferente do sentido literal. A alegoria tem suscitado uma ampla rede terminológica, inserindo-se desde a metáfora até a sátira, passando pelo símbolo, a fábula, a parábola, a prosopopeia, o paradoxo, dentre outros.

Seguindo a etimologia do vocábulo, alegoria é um discurso que fala de uma coisa referindo-se a outra ou uma história que sugere outra através do emprego de imagens ou figuras de lin- 
guagem. Pode funcionar com certo aspecto material na dissimulação ou no revestimento de uma ideia (um conteúdo manifesto) ou ainda com aspecto moral, idealizado ou ficcional (como um conteúdo latente). Visto que a narrativa da alegoria consiste na concretização do mundo abstrato ou do mundo imaginário, a alegoria também pode ser não verbal ao expressar-se como artifício simbólico (ou como signo) na obra de arte. Alegoria é uma figura de linguagem que está inserida no que se classifica como "figuras de palavra", ou seja, relaciona-se à semântica, e encontra seu significado nas abstrações.

Em regra geral, a alegoria reporta-se a uma história ou a uma situação/condição que narra com sentidos duplos, figurados e sem limites textuais (podendo ocorrer tanto num poema como num romance). A alegoria transforma a ideia (literária) ou a forma conceitual de um elemento (artístico) numa nova imagem, apesar do conceito original poder ser mantido. $\mathrm{Na}$ alegoria, desaparecem as originais significações para serem atribuídos múltiplos sentidos, na provocação de um efeito com um amontoado de escombros usualmente antecedentes. Ao libertar a alegoria de seu traço anacrônico, atrelado a um conceito anterior, Benjamin pretende reabilitar a história e a temporalidade como fulcro de análise do mundo da cultura.

A marca da alegoria é o distanciamento das coisas do seu sentido original; é a alienação da sua verdadeira essencialidade. A alegoria incita um abismo entre o sentido das coisas e as próprias coisas; ela nasce e renasce da fuga perpétua de um sentido último - ou da revelação de uma verdade oculta. No universo da alegoria não existe mais ponto fixo e imutável, nem no objeto, nem no sujeito, que através da interpretação alegórica garanta a verdade do conhecimento. Uma alegoria não representa as coisas tais como elas são, mas pretende antes nos dar uma versão de como foram ou podem ser; a alegoria resulta na imagem adequada de um novo conceito.

A alegoria, então, relaciona-se com o signo linguístico porque no mundo histórico as coisas deixaram de ter sentido em si mesmas; o nome não é mais a coisa, mas todos os fatores da linguagem - as coisas, as palavras e o intérprete estão inevitavelmente submersos na historicidade. Consequentemente, a alegoria conhece a história apenas como a história do declínio, como um movimento direcionado ao passado, não ao futuro. A alegoria, portanto, tem sua base no duplo princípio da subjetividade e da historicidade reciprocamente implícitas no Barroco.

Arrancado do seu lugar e função, descontextualizado, o fragmento pode reunir-se ou ser reunido com outros fragmentos 
isolados da realidade, criando assim seu sentido como alegórico e não resultante do contexto original dos fragmentos. Uma coisa individual é tomada como fragmento, arrancada de um todo para absorver o sentido alegórico, pois somente assumida como fragmento a arbitrariedade subjetiva do ato alegórico pode provê-la de novo sentido, procedimento que pode ser entendido como um resgate, porque sem ele a coisa permaneceria condenada à transitoriedade, muda e sem sentido. Mas vale dizer que esse sentido que o alegorista atribui à coisa nada tem a ver com seu sentido original, com a ideia que ela poderia exprimir antes da alegorização, já que para um objeto ser alterado a partir de sua significação alegórica ele tem de ser privado de sua vida, ou seja, o alegorista deve extrair o objeto de sua conjuntura para que ele possa se ressignificar - o objeto é transformado em algo distinto.

A alegorização acontece essencialmente como fragmentação. Considerando a subjetividade e a historicidade como categorias pragmáticas, surge uma ambiguidade como consequência, já que podem ser entendidas como subjacentes à alegoria e como princípios fundamentais, determinando a constituição do seu sentido. As coisas que o alegorista opta por usar são tidas como significantes e o resultado é a conexão subjetivamente instaurada pelo alegorista. $\mathrm{O}$ alegorista, alterando as coisas do significado original em novo significante, aponta as condições específicas sob as quais as coisas serão capazes de adquirir novo significado no mundo histórico.

Seligmann-Silva (2009, p. 18) vem ressaltar que Benjamin fundou uma teoria da tradução que se volta contra as concepções tradicionais de conhecimento sobre a obra de arte e sobre a verdade. A teoria da alegoria, no entanto, é uma das vias da crítica da representação. Ao invés da totalidade orgânica, o tropo alegórico sempre serviu como meio para uma expressão indireta - a alegoria é como uma cadeia infinita de passagens entre significantes que remetem a outros significantes. No contexto da alegoria, a imagem é apenas marca, monograma da essência, não a essência no seu invólucro. A imagem barroca é alegórica, escritural e testemunha da ausência de ancoragem para a significação - a única fonte para a nova significação é justamente o que se torna transitório na época; a pré-disposição da significação infinita tanto das palavras como dos objetos numa historicização da natureza.

A alegoria, portanto, como "outro dizer", possibilita um novo contorno plástico para a expressão da natureza. Nas mãos do alegorista, o objeto torna-se outra coisa no âmbito 
de um saber oculto, com característica de emblema: "[...] isso constitui o caráter escritural da alegoria. Ela é um esquema, e como esquema, objeto de saber que só se torna imperdível para ele quando fixado: ao mesmo tempo imagem fixa e signo que fixa" (BENJAMIN, 1984, p. 359).

\section{As pinturas alegóricas}

Em relação à terceira questão posta neste estudo, pode-se dizer que uma leitura alegórica da obra visual de Nuno Ramos se torna possível justamente devido à semelhança com o processo técnico dadaísta (Figura 3), que utiliza colagem-montagem e que se configura por meio da aglomeração de materiais híbridos e de elementos efêmeros que adquirem um caráter simbólico na representação do descarte e da banalidade da vida da contemporaneidade. A intenção é amontoar materiais que no curso da vanguarda dadaísta (século XX) foram adicionados à tela, mas que, na contemporaneidade, podem adquirir novo sentido conceitual e estético. Nuno Ramos (como um alegorista) introduz outro sentido referencial e funcional à matéria para que esta última, com caráter simbólico, possa intervir na obra de arte com novos significados - como diz Naves (1997, p. 191), com o "realismo [que] significa uma atitude crítica em relação ao estatuto contemporâneo da realidade".

Nuno Ramos cria uma espécie de atmosfera encantada pós-vanguardista quando aglomera de forma grotesca fragmentos e materiais que são objetos simbólicos no cotidiano atual. À moda do princípio Merz dadaísta, a seleção de objetos usualmente reconhecidos pela sua efemeridade, a exibição desordenada das materialidades e o fluxo das suas descontinuidades são atualizadas pelo artista como um mosaico da representação de "uma crítica à sociedade de consumo: ao excedente, ao desperdício que indica exclusão social, à lógica, enfim, da obsolescência, inseparável da mercadoria" (FABBRINI, 2002, p. 115). Assim como fez Schwitters em seus Merzbau', a obra visual de Nuno Ramos tem o efeito de um suporte que representa "a negação de tudo o que é história, de qualquer finalidade, de qualquer ordem do dia. As coisas que, tomadas da realidade [...], podem ser dissociadas de uma crônica cotidiana amorfa, opaca, desordenada" (ARGAN, 1992, p. 359). As coisas recolhidas e combinadas por Schwitters e compostas no quadro foram descartadas pela sociedade por não servirem mais, por já terem cumprido suas funções. Ainda para Argan, esse processo é a "trama intrincada e, no entanto, claramente legível da existência. Ou, talvez, do inconsciente, que,
Figura 3

“Merzbild Kijkduin”, Kurt Schwitters, 1923.

Técnica mista sobre tábua. Museu do Reino Sofia, Madri. (Foto de jan. 2013)

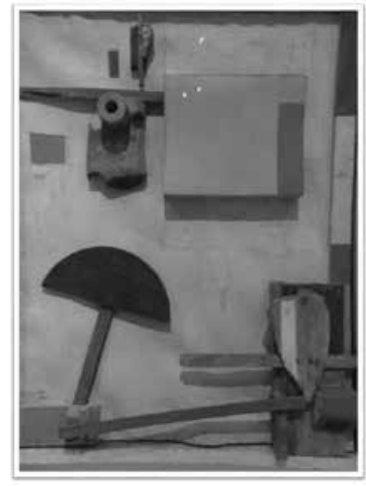


por motivação profunda, determina o fluxo incoerente da vida cotidiana" (ARGAN, 1992, p. 360).

Nos Quadros sem títulos de Nuno Ramos (Figura 4), as massas, texturas e cores dos elementos plásticos são combinadas dinamicamente com a movimentação dos contrastes, num tipo de justaposição acumulativa, à moda das técnicas das colagens Dadaístas, evidenciando as possíveis relações da natureza entre o fosco e o brilhante, a dureza e a maleabilidade, a forma reconhecida e o desconforto visual que causa um aspecto de estranhamento.

Figura 4

Nuno Ramos, Sem título, materiais diversos, $230 \mathrm{~cm} \times 440 \mathrm{~cm} x$ $310 \mathrm{~cm}, 2008$. Exposição "Mar Morto" na Galeria Anita Schwartz, RJ, 2009.

Disponível em: <http://www. anitaschwartz.com.br>. Acesso em: 28 nov.2013

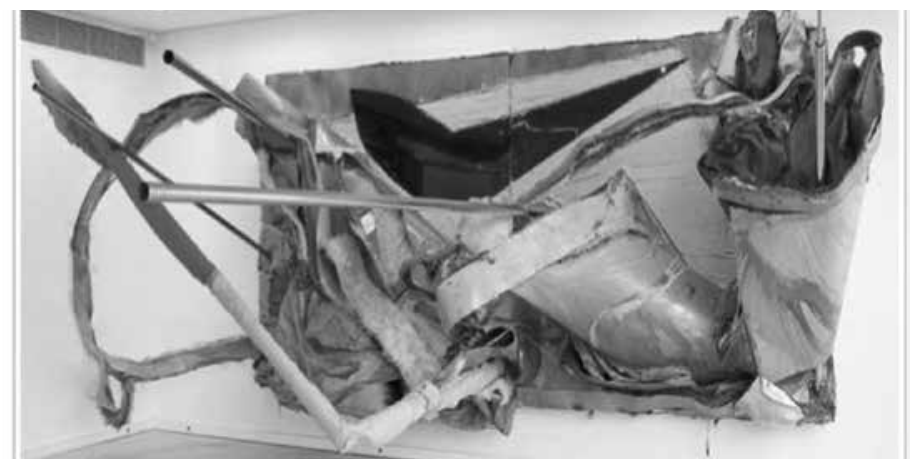

O aspecto ameaçador da obra de Nuno Ramos não está apenas no fato de que a cada instante os quadros ameaçam desfazer-se, mas principalmente no fato de que as obras não liberam as ações unicamente para um campo simbólico ou imagético, segundo Tassinari (1997, p. 186). A matéria, recusando-se a desaparecer por trás do significado, permanece como uma força que o desestabiliza a fim de ameaçar a forma. Nessas obras, especificamente nas pinturas do período citado, nem o significado nem a forma fluem ou se cristalizam. Sendo assim, o aspecto de degradação insinuado na obra tanto não impede a alusão (ou a evocação) de um sentido alegórico, como o deixa indefinido e interrompido, como algo que virá - o artista dispõe de sua arte para se relacionar com a vida, com seu corpo, com sua história e sua memória.

$\mathrm{O}$ próprio recurso à sobreposição de temporalidades, temas, escritas, imagens e materiais contraditórios e à não hierarquização do olhar para a apreensão da forma pictórica anula qualquer possibilidade de síntese coerente, seja formal, seja nos termos de inscrição de significados. A rudeza das formas, de materiais e de texturas e a ambiguidade de sentidos no constante vira ser de múltiplas conexões, no tempo e no espaço, 
em vez de potencializarem identidades formais ou de sentido, parecem intensificar uma ação de troca e reversibilidade, transmutação, deslocamentos e estranhamentos.

Nuno Ramos se apropria dos valores conceituais e dos padrões estéticos dadaístas para instaurar a poética da contemporaneidade de suas obras. Dessa maneira percebe-se que essas estratégias ou procedimentos alegóricos servem, inclusive, a um anseio do artista em se resguardar da tradução, ou mesmo da institucionalização, da obra como um símbolo estanque, temporal e fixo, já que os procedimentos técnicos permitem interlocuções anacrônicas. $\mathrm{O}$ artista recorre aos procedimentos e técnicas dadaístas a fim de reestruturar (e atualizar) seu discurso artístico - enfim, o artista opera a montagem de elementos para a reapresentação da obra, num trabalho inegavelmente que resulta em metáforas da memória.

Como uma atitude alegórica, Nuno Ramos resgata a estética dadaísta, com recurso à fragmentação da montagem matérica que é ressignificada na atualidade. Os materiais utilizados funcionam como fragmentos, são coisas, apesar de parecerem outras coisas - procedimento que remete ao passado, mas que o artista reapresenta como pintura de um corpo orgânico que traz "a experimentação, na qual a ausência de regras é menos um desafio às normas" e mais uma maneira de constituir a questão da criação artística que permita a significação, já que a "liberdade do artista não passa por um conhecimento artístico e sim por uma vontade espontânea de significar, através da arte, sua perplexidade em relação ao estar no mundo". (TASSINARI, 1997, p. 186).

Peter Bürger, na sua Teoria da vanguarda (1987, p. 95), utiliza o conceito de alegoria como uma possível categoria central de uma teoria da arte de vanguarda. Indo além de algumas características desse conceito e aplicando-o à concepção da obra de arte, o autor diz que o objeto, à medida que pode ser uma figuração do concreto, pode vir a ser uma recusa da continuidade da história. Ou melhor, ao estudar o conceito de alegoria, Bürger aponta a fragmentação e a descontextualização como resultantes da ação do artista-alegorista que fora capaz de extrair um elemento do seu contexto original, isolando-o e despojando-o da sua função inicial para uma nova representação. Ainda que a alegoria seja um modo de transformar o sentido original, ela direciona o olhar para o passado, pois faz recordar que as coisas, mesmo descontextualizadas, tiveram um sentido e um significado em si mesmas, antes de serem incluídas em outro contexto.

Ainda para Bürger (1987, p. 132), o conceito benjaminiano de alegoria pode ocupar a categoria central de uma teoria das obras 
de arte de vanguarda porque o artista desse tempo arrancava ou desenraizava seus materiais de um contexto em que ainda tinham função e significado para fragmentá-los como signos vazios, apesar de predispostos a novos significados. O artista dadaísta montava sua obra sobre fragmentos; não produzia uma obra como um todo orgânico, mas tencionava um sentido que era atualizado ao reapresentar os fragmentos. A obra apresentava-se como artefato, isto é, como um produto artístico intencionalmente servindo-se da montagem e, muitas vezes, vinha traduzir o imaginário da aparência fragmentada da totalidade.

As obras visuais de Nuno Ramos apresentam os elementos plásticos como imagens simbólicas que são desfeitas em outras imagens, funcionando, portanto, com caráter de alegorias e, no entanto, com o formato de antiobjetos. O elemento matérico (alegórico) está livre do imediatismo, e sua inserção na obra de arte tem efeito visual de multiplicação, de sobreposição de elementos heterogêneos, de estratificações de imagens, de códigos e de reproduções de obras e imagens intencionalmente alegorizadas.

A alegoria é a alegoria de um objeto, uma configuração visual da multiplicidade. No entanto, a alegoria não instaura na obra somente o simulacro visual, mas uma sobreposição e repetição conjuntamente relevantes no campo conceitual. O elemento alegórico não é o que pode ser reproduzido, mas o que traz em si o próprio reproduzir-se: a reprodutibilidade enquanto tal. Dessa forma, a alegoria é sempre algo já reproduzido e que se adéqua culturalmente, já que implica a reprodução de si mesma e se autodefine. Mais do que uma repetição, o objeto alegorizado funciona como reprodução de sentidos permanentemente atualizados para sua autorrepresentação.

Desde as obras cubistas de Picasso e/ou de Braque, passando pelo processo Merz à época dadaísta, a técnica de colagem como uma representação artística já estabelecia relação com o processo alegórico. Em outros termos, ao arrancar um fragmento de um jornal (ou outro elemento textual qualquer do dia a dia) e colocá-lo numa tela, modificando o contexto dessa tela, já havia uma relação intertextual entre o quadro (suporte) e o jornal (fragmento alegórico). A semantização do fragmento de jornal e a do quadro, por exemplo, foi realizada por essas linguagens das vanguardas citadas acima através do processo de reconstrução e relação entre quadro e jornal. A colagem, além de funcionar como uma nova técnica representacionista diferente da arte tradicional, vinha romper com o curso mimético da arte, ao introduzir a montagem de elemen- 
tos e objetos cotidianos como uma técnica que representava palavras e imagens com efeito simbólico.

Abordar a presença da alegoria na arte da contemporaneidade pode parecer uma questão deslocada; no entanto, a retomada da questão sobre a alegoria na atualidade constitui um modo de abordar a imagem artística (a obra de arte) não como aquilo que apenas está exposto, mas entender como ela retoma a recorrência de valores estéticos e culturais. A teoria difundida por Benjamin sobre a alegoria no período barroco pode ser empregada para percebermos os procedimentos conceituais atuais da arte, no que dizem respeito à apropriação, à profusão e à duplicação.

Seligmann-Silva (2005, p. 137) reaquece essas questões das vanguardas artísticas quando diz que a leitura da arte da pós-modernidade, com base em conceitos benjaminianos, parece-lhe absolutamente pertinente a partir da intermediação das fronteiras entre as palavras e as imagens de uma escritura cifrada. Quer dizer, para o autor, as imagens que impregnam as produções culturais atuais são saturadas de histórias traumáticas coletivas e individuais, assim como de encenações autobiográficas referentes à exposição do corpo como objeto/abjeto. Afinal, a alegoria pode ser reconhecida pela pós-vanguarda como um novo código cifrado com o qual não apenas se tem acesso aos registros das gerações passadas, mas com o qual podemos estruturar e referenciar tecnicamente nosso presente. Conforme Kossovitch, "a arte da pós-vanguarda se apropria, sem hierarquizar, de tudo quanto a antecede e o dispara com procedimentos combinatórios" (KOSSOVITCH apud FABBRINI, 2002, p. 19).

\section{Os princípios da linguagem dadaísta na construção do antiobjeto da contemporaneidade}

Formado em 1916, em Zurique, por jovens franceses e alemães que fogem do serviço militar à época da Primeira Guerra Mundial, o Dadaísmo é um movimento de negação e de reação à época. Tal atitude não passa de uma "grande explosão de atividades que tem por objetivo provocar o público, as noções tradicionais de bom gosto e a libertação das amarras da racionalidade e do materialismo" (STANGOS, 2000, p. 85).

Dadaísmo (também chamado de Dadá) é uma palavra francesa que significa, entre outras coisas, "cavalo de pau" e passa a ser considerada a marca da arte espontânea, livre de conceitos morais e sociais que são divulgados no espaço conhecido como Cabaré Voltaire. Ao grupo de artistas dadaístas 
pouco importa a circunstância que deu origem ao nome e muito menos a acepção anterior da palavra - a partir de então, a palavra dadá passa a designar um estado de espírito.

Por meio da arte, os dadaístas propagam a visão que têm do mundo, na qual predominam atitudes subversivas, niilistas, anárquicas, céticas e destrutivas. O movimento dadaísta se declara contra tudo e contra todos, inclusive contra si mesmo. A arte nada tem a ver nem com o belo nem com o feio; ela visa, acima de tudo, à originalidade, expressar-se como nunca antes. Assim como a arte não sintetiza a beleza, não representa igualmente a verdade, a verossimilhança. Os artistas amaldiçoam a arte como mimese.

Desse modo, a arte dadaísta pode ser definida como construção conceitual e fabricação de novos parâmetros estéticos no lugar da mera repetição de modelos e convenções vigentes até então. A arte não precisa de inspiração de outras artes antecedentes. Ela não deriva nem da razão, nem da fantasia, tampouco do sentimento, mas deve resultar, na medida do possível, de um processo automático e mecânico.

Os princípios do Dadaísmo são difundidos em pinturas, esculturas, poesias e músicas. A pintura é uma forma amplamente utilizada, e os pintores dadaístas são guiados por uma anarquia instintiva, não hesitam em pormenorizar as formas, as técnicas e a temática das pinturas. Apesar de algumas manifestações públicas ainda persistirem isoladamente com caráter libertário em relação à expressão artística e literária, nota-se que, por volta de 1921, o movimento dadaísta é pulverizado aos poucos em virtude de outros tantos movimentos e correntes artísticas que se propagam em várias regiões. Como mais um movimento de vanguarda do século XX, o Dadaísmo também contribui com novos parâmetros artísticos, quando seus participantes inovam ao atribuir valor estético a objetos e a elementos usuais do cotidiano. Na verdade, o que é alterado é o conceito que se aplica a um determinado elemento/objeto/material.

Para tanto, os dadaístas utilizam objetos comuns do cotidiano para apresentá-los num novo contexto conceitual e artístico. Apesar de serem usualmente vistos no dia a dia, esses objetos, quando deslocados de sua utilidade funcional, são empregados pelos artistas como simuladores de outros valores artísticos instituídos por meio de suas formas, texturas e cores. Novas configurações conceituais e estéticas se impõem, contrariamente ao que até então se entendia e se reconhecia como arte.

E é com os ready-made, de Duchamp que há, pela primeira vez, o desvio da atenção do espectador para a importância do 
contexto artístico na definição e avaliação de uma obra de arte; em outros termos, a importância do campo espacial-conceitual e do objeto estético provoca uma questão inovadora: "Quais são as características e condições que definem um objeto como obra de arte?" (ELGER, 2005, p. 8o). Duchamp suprime sumariamente a forma: resta a ideia. Como costumava dizer, não há solução porque não há problema. Submete a arte ao mundo da representação da idealidade pura, tornando-se o mais platônico dos artistas da modernidade. Quando propôs o ready-made, Marcel Duchamp dissociou inteiramente a questão da plasticidade da noção de arte. Ao belo e ao bom gosto, reagiu com a indiferença. Dividiu, com a impassibilidade, o mundo da arte em duas partes: antes e depois do ready-made. Naquele momento, Duchamp dava à forma o caráter de acidente, desqualificando-a. O objeto, agora como objeto de arte, tem valor de pensamento e menos importância de forma sensível: o objeto, portanto, é mais ético do que estético e declara o fim do processo artístico como fazer, habilidade e virtuosismo.

Na concepção do artista, a função da obra de arte é conseguir estabelecer, inclusive, uma relação com a realidade do cotidiano. Nesse sentido, Duchamp se aproxima do hibridismo como um dos principais vetores plásticos de sua obra ao atingir um sentido extrapictural a partir da união da pintura com a escritura.

O estranhamento, no entanto, passa a ressoar na relação entre o espectador e a obra de arte. O papel do espectador torna-se mais incisivo, pois o ato de contemplar uma obra não basta para entender as novas proposições estéticas. A percepção cede lugar à interpretação, e o olhar passa a exigir o pensamento, uma ação intelectual. Afinal, como o público poderia se aproximar de um objeto que, sendo usual no cotidiano, torna-se distante somente por estar num espaço de exposições de arte? O desejo de confrontar o público com o conceito da arte dadaísta e com as funções originais do museu faz de Duchamp um artista que amplia os territórios e a natureza do fenômeno artístico.

Kurt Schwitters, contemporâneo de Duchamp (apud CHIPP, 1993, p. 388), afirma que ocorre uma renúncia à reprodução de elementos naturais (mimese) em favor de abstrações causadas com elementos pictóricos, ou melhor: que ao conciliar elementos entre si, o artista não tem a intenção de reproduzir a natureza, mas de difundir uma expressão conceitual na obra de arte. Com a valorização estética de seus elementos, o conceito primordial da arte dadaísta sustenta valores artísticos que ainda estão um pouco indefiníveis e, aparentemente, à época, sem propósito. 
No caso dos ready-made, o que Duchamp fez foi remover objetos cotidianos do seu meio natural, libertá-los da sua função e apresentá-los como obras de arte em exposições. $\mathrm{O}$ resultado é uma provocação dos hábitos de irreflexão do espectador em termos de percepção e avaliação da arte. Schwitters, da mesma maneira, recorre ao material não artístico e procura, delimitando uma parte do objeto e o realçando enquanto estrutura composicional, trazê-lo de novo para a arte tradicional.

Os materiais selecionados por Schwitters para desenvolver os princípios conceituais e estéticos do método $M e r z^{2}$ faz desse método um ato artístico que produz, por meio da junção e justaposição de materiais organizados aleatoriamente na composição, uma nova forma estética e um novo viés conceitual da expressão artística. Para a concepção e a produção da obra, qualquer elemento material poderá servir como elemento artístico. Schwitters diz que há uma vantagem sobre a pintura a óleo, já que pela arrumação de materiais divergentes consegue opor cores, linhas e formas umas em relação às outras - "é a sua irônica resposta ao estado de espírito da época, cujo entusiasmo pela tecnologia estava em violenta contradição com o caos político dominante" (ELGER, 2005, p. 80). Para o Dadaísmo, não há regras nem sequência. $\mathrm{E}$ o desafio é justamente este: confrontar todos os elementos compositivos em detrimento de seu equilíbrio estético e em favor de sua (nova) afirmação conceitual.

Preocupado em ridicularizar a arte vigente, o Dadaísmo entrega-se a um intenso experimentalismo e (re)descobre várias técnicas de composição. A obra de arte é entendida como produto do acaso, sem interferência psíquica, nem consciente, nem inconsciente. Mesmo quando o processo e a técnica de construção da composição são calculados, o resultado é imprevisível, um caos inovador. A montagem é uma técnica predominante durante o movimento dadá. De forma original, a arte dadaísta recorre à técnica que faz da seleção e da reorganização de objetos selecionados, um elemento com valor estético a partir de sua nova conceituação artística. Assim, a criação artística altera o olhar do espectador, que amplia a função do objeto, já conhecida, a partir da sua nova função ocasionada pelo deslocamento e pela recontextualização alegórica.

Uma questão que se torna relevante neste artigo é justamente aproximar as possibilidades testadas no Dadaísmo com as pinturas (os Quadros sem títulos) da década de 1990 produzidas pelo artista Nuno Ramos. Ou melhor, torna-se intencional relacionar a (re)apresentação do objeto estético por meio de suas possíveis perspectivas conceituais - assim como 
Duchamp o fez - com a técnica da linguagem plástica do princípio Merz de Schwitters, a fim de entender a relevância da configuração pictórica de Nuno Ramos na contemporaneidade.

Ao adotar o senso dadaísta de jogo e acaso, Nuno Ramos desloca o valor artístico dos processos de criação subjetiva para métodos intencionais de confluências conceituais que se expandem entre arte e invenção/experimentação de modo que os materiais adquiram caráter de "antiobjeto". Como uma obra de arte concentra vieses de rupturas e referências, pode-se dizer que o artista Nuno Ramos, com o acúmulo e as sobreposições de objetos e materiais cotidianos, dá possibilidade, recorrendo ao próprio Duchamp, para que "o ato criador tome outro aspecto quando o espectador experimenta o fenômeno da transmutação [...] quando estabelece o contato entre a obra de arte e o mundo exterior, decifrando e interpretando suas qualidades intrínsecas" (DUCHAMP apud BATTCOCK, 1986, p. 74). As apropriações feitas por Duchamp, os ready-made, estão na ordem dos questionamentos de valor e utilidade ou, como ele mesmo afirma, são um jogo para desencorajar a estética. A convivência entre as distâncias temporais (referente à origem dos materiais e à sua disseminação alegórica) aciona tudo aquilo que não está apenas na obra, mas nos múltiplos tempos (materiais) por ela apresentada.

Nuno Ramos, assim como Duchamp, não está preocupado com o produto formal, mas sim em compor, por meio do objeto de massa, uma reapresentação do objeto artístico que enfatiza a esteticidade da obra e a renovação do conceito do que se entende como belo. A obra de arte se constrói no momento em que um objeto comum de seu ambiente funcional e cotidiano é combinado a outros para a alteração de seu contexto lógico. A partir daí, as articulações mentais do artista com o acaso estético decorrente dos deslocamentos (imprevisíveis) de objetos propiciam-lhe construir assemblages com tom de paródias, evocando sua observação aguda sobre o mundo que o cerca na articulação das partes e dos sentidos (além das atitudes de intervenção sobre a realidade), o que não faz dele um sujeito lírico absorto em seu drama existencial.

A dinamização de objetos comuns, alterada por efeitos de imaginação, pela precariedade dos materiais e pela leveza dos volumes, só vem confirmar o nonsense da operação artística. Na verdade, a própria noção de suporte é questionada: os objetos desorganizados tornam-se móveis, frágeis, agentes de uma estrutura incongruente, sustentada por todos os objetos e ao mesmo tempo por nada. O caráter serial do trabalho, por sua 
vez, afirma obsessivamente a duplicidade ou, ainda, a multiplicidade. Não há lugar para o original, para a unidade, ideia que remonta, novamente, aos processos industriais e à repetição e que fundamentou a arte dadá. O objeto, antiobjeto, na obra de Nuno Ramos, torna-se elo de um processo em cadeia, indistinto, como manobra de criação plástica. As obras apontam para várias leituras, e os objetos acabam por assumir o caráter plástico-estético de assemblage dadaísta: uma forma dissociativa, feita por acumulação de pedaços, por justaposição de partes, uma antiforma. A indefinição dos contornos dos objetos contribui com a indistinção dos produtos feitos em série, tão "insignificantes" esteticamente quanto os ready-mades duchampianos.

A obra de Nuno Ramos, ainda assim, está próxima dos parâmetros da arte dadá, lançada por Duchamp, quando permite que o espectador transcenda a forma aparente dos objetos para reconhecê-los como ideias conceituais passíveis da fruição estético-visual relacionadas à contemporaneidade. Para tanto, os objetos materiais funcionam como procedimentos alegóricos atemporais. $\mathrm{O}$ excesso visual reforça a desordem entre os objetos usuais do cotidiano, ou seja, a estrutura visual formada pelos excessos de camadas de objetos ressalta os volumes provocados pela maleabilidade das formas com as texturas heterogêneas dos objetos utilizados. Materiais divergentes passam a ser vistos juntos e a compor uma aparência híbrida (inevitável) de conflitos compositivos. Desse modo, apropriando-se do objeto-matéria, o artista é capaz de (re)configurar o antiobjeto em elemento alegórico, ou melhor, de atualizá-lo "para que possa figurar o imaginário atual como decorrência do imaginário da modernidade artística" (FABBRINI, 2002, p. 115).

Aproximando a linguagem dadaísta (mais precisamente com Duchamp) à obra visual de Nuno Ramos, pode-se dizer que o conteúdo da obra de arte está em si mesmo e a partir de si. Ou melhor, o conteúdo procede de uma matéria resultante de uma composição técnico-artística com abordagem propositadamente conceitual. O acesso ao conteúdo-forma na obra de arte ignora o objeto enquanto tal, pouco importando a representação aparente de si mesma; o processo matéria-forma exige a intervenção do conteúdo. A obra traz a absoluta prioridade dos motivos expressivos sobre as resoluções técnicas, ao mesmo tempo em que ambos se equivalem para, em decorrência, partirem dos elementos conceituais em busca dos demais conceitos estético-visuais. Portanto, a inseparabilidade entre forma e conteúdo reafirma os processos conteúdo-forma e matéria-forma coincidentes. 
As obras visuais de Nuno Ramos não trazem apenas uma operação de abstração dos objetos em materiais, isto é, da substituição da aparência dos materiais já usados no Dadaísmo por uma imagem abstrata onde os materiais perdem as formas e as cores. Trazem, sim, a emissão das formas que se alegorizam no território da imaterialidade; a redução do objeto, do material a pensamento, do mundo a vestígio alegórico, da proliferação da imagem da imagem de um objeto. Conforme Duchamp, quem faz a obra é aquele que olha, parte da recepção do observador a valorização do fragmento em detrimento do todo. Para os dadaístas, o ambiente não traz em si qualquer qualidade estética, mas cada contemplador pode interpretar e experimentar esteticamente as coisas que o compõem, desviando-as da finalidade utilitária que lhes é atribuída por uma sociedade também estritamente utilitária. "A atividade especificamente estética tende não a modificar as condições objetivas da existência, e sim a oferecer o modelo de um comportamento livre de qualquer direcionamento." (ARGAN, 1992, p. 358).

As experiências do observador, na contemporaneidade, contribuem para o redimensionamento das relações entre produção artística, fruição e público, ou seja, para o redimensionamento cultural da arte. $\mathrm{O}$ artista contemporâneo não é mais o que realiza a obra apenas para a contemplação, mas o que propõe situações que também devem ser experimentadas pelo espectador. A arte se liberta da obra, tornando-se uma situação, um processo. Ao apropriar-se de objetos existentes, criando novamente ready-mades, transformando e reificando os antiobjetos, as ideias e os conceitos, enriquecem os primeiros semanticamente.

Conforme Gullar (1999, p. 294) a significação alegórica atribuída aos objetos torna-se imanente à sua própria forma de antiobjeto atualizado. Mesmo que (a)pareça com caráter de objeto anônimo, o antiobjeto presta-se à criação artística através da valorização de suas novas características como objeto híbrido e efêmero. Em outros termos, o artista atribui ao antiobjeto, por meio da técnica e da temática, a construção de um novo espaço pictórico contemporâneo. Apesar de provocarem um amálgama que trilha na tridimensionalidade, os não objetos incorporam-se à obra de arte por meio de um processo artístico que é mais relevante do que a própria obra finalizada. A valoração do objeto não artístico e sua aplicabilidade como uma ideia que se alegoriza em um não objeto, que se concentra em registros e lembranças, pode "propiciar o revide de que a qualidade do objeto 
não importa e que a função da arte pós-moderna não é agradar os sentidos, mas prover uma investigação fundamental dessa mesma arte e da realidade" (BATTCOCK, 1986, p. 222).

O espaço da tela, todavia, é apresentado como campo de positividades. Não há nada escondido. Não há vazio negativo. Há, sim, o objeto na sua essência, um antiobjeto que completa um espaço artístico e materializa o tempo da contemporaneidade por meio de jogos visuais, que por sua vez destacam impressões estéticas muito particulares que se configuram através da figura-fundo, do claro-escuro, do rígido-escorregadio, dentre outros. A relação entre o que é visível e o que se torna dizível ressalta a discrepância das formas, cores e texturas.

É nessa atração recíproca entre o processo orgânico e a assimilação das qualidades dos objetos e materiais que emerge singularmente (em cada obra) uma dimensão conceitual, como culminância do desenvolvimento do conhecimento junto à experiência-matéria. A exposição de um objeto "não artístico" pouco usado nos suportes convencionais para obras de arte acarreta o estranhamento (ou uma forma degradada de percepção) ao haver o deslocamento de seu sentido original. Ainda conforme Fabbrini (2002, p. 136) o artista que segue nesse processo, como faz Nuno Ramos, nunca polemiza a ideia para o público nem infringe a crítica artística com suas reflexões sobre o estatuto ou as probabilidades da arte contemporânea.

A arte "pós-moderna", aos olhos de Pedrosa, é, dessa forma, uma antiarte no sentido de que "os valores propriamente plásticos tendem a serem absorvidos na plasticidade das estruturas perceptivas e situacionais" (PEDROSA apud AMARAL, 1981, p. 206). As questões relacionais entre conceito, ideia e experimentação são os princípios com os quais a arte da contemporaneidade tem se preocupado. Artistas como Lygia Clark e Hélio Oiticica, em fins dos anos 1950 e início dos 1960, buscavam, assim como Duchamp, objetos insólitos e materiais alternativos que trouxessem uma poética de uma linguagem artística inovadora. A proposta da "antiarte" 3 , no entanto, advinda dos estilos artísticos dos "ismos" da época moderna, é incorporada à História da Arte também por Nuno Ramos com a (re)apresentação das "coisas-objetos". Revendo a própria palavra "moderno" do latino "modo", que quer dizer "agora mesmo", a época moderna não consegue funcionar, como é tradicionalmente conhecida, como ruptura. Ou melhor, o desmoronamento das convenções artísticas pelas vanguardas modernas corresponde a novas utopias estéticas, invenções e exercícios de criatividade plástica. A antiarte não tem a intenção de reagir contra os conceitos da arte 
do passado, mas sim de criar novas condições experimentais em que $o$ artista possa assumir o papel de propositor mediante, inclusive, ao imaginário coletivo.

A contemporaneidade traz a antiarte como uma relação da vida com seus objetos cotidianos (e vice-versa). A antiarte é a desestetização e a "desdefinição" da arte com viés moderno e vanguardista. A antiarte não se preocupa com a forma ou com a representação do que é belo; exemplo disso é a obra de Nuno Ramos, que, ao abandonar o realismo das formas, a verossimilhança do objeto conceitualmente construído no Dadaísmo, a moldura que limita a representação mimética e ao alegorizar materiais não artísticos, redefine ("desdefine") a arte contemporânea retornando às questões que permeiam a arte culta e a arte de massa - questões sociais discrepantes que se fundem na representação estética e conceitual da antiarte atualizada.

O que é tido como moderno só pode ser suplantado por outra linguagem tão moderna quanto a anterior, e é por essa razão que Nuno Ramos (ao refazer o que no Dadaísmo fora o estopim para a concepção da arte moderna) contribui com a construção de um imaginário da contemporaneidade. A antiarte faz com que o artista revisite (alegorize) os objetos e estenda seu deslocamento cultural a partir de uma intervenção estética que se relaciona à sua própria subjetividade e à própria significação social desses objetos. A antiarte traz o hermetismo e o subjetivismo da banalidade cotidiana - ela é a fusão da arte com a vida; é a relação da vida com os objetos que o artista dispõe cotidianamente. A desestetização, a desdefinição da arte da contemporaneidade, põe um fim à beleza, à forma e ao valor supremo da mimese retratada a óleo. Com materiais não artísticos, como plástico, papelão, areia etc., o cotidiano é estetizado pelo design na forma de objetos produzidos em série. Enfim, a partir da proposta plástica do Dadaísmo, que alegoriza os objetos do/ no caos cotidiano, o que se torna mais importante é o gesto do processo conceitualmente inventivo e não necessariamente o aspecto estético da obra apresentada.

A desestetização da arte coloca as apropriações de objetos industriais e de objetos da era tecnológica (da informação e da comunicação) como reapresentações artisticamente alegóricas combinadas à exaustão, com a consequente degradação dos objetos. As pinturas (os Quadros sem títulos) de Nuno Ramos em estudo reapresentam os materiais necessariamente atrelados às suas articulações visuais e conceituais com o cotidiano, a fim de enfatizar os questionamentos a respeito de suas próprias naturezas mercadológicas e usuais na contemporaneidade. 
A arte atual (desestetizada) passa a ser um sinal da investigação do primado da forma, das técnicas e de suas convenções. Ou seja, em vez de restringir-se ao que pertence estritamente à experiência visual, a arte torna-se experiência intelectual que lança mão de outros códigos e que sai do domínio do estritamente apreciável: complementando o valor estético, $\mathrm{o}$ ato mental; em lugar do juízo de gosto, a indiferença plástica; ao invés da racionalidade mimética, a estranheza da composição matérica; e, ao avesso do fazer, o escolher.

NOTAS

1. De acordo com Argan, o termo Merz também é casual como o nome Dadá. Criado por Schwitters, Merzbau "é uma espécie de coluna, quase um totem, feita de coisas encontradas ao acaso e acrescidas a outras, dia após dia. Seus quadros (se assim se pode chamá-los) são compostos de tudo o que, topando-se por acaso sob as vistas ou ao alcance da mão, chamou sua atenção por um instante, ocupou sua vida por um momento".

2. No texto programático sobre a pintura Merz, Kurt Schwitters diz que as pinturas Merz são obras de arte abstratas. A palavra Merz significa essencialmente o resumo de todos os materiais concebíveis para objetos artísticos, e tecnicamente - em princípio - a validação igual dos materiais individuais. Na pintura Merz, a tampa da caixa, a carta de jogar ou o recorte do jornal tornam-se a superfície, o cordel, o traço de pincel ou de lápis torna-se a linha, a malha de arame, o excesso de tinta, ou o papel antiaderente tornam-se o verniz e o algodão torna-se a macieza.

3. A antiarte advém de duas grandes tendências da arte moderna, a construtiva e a duchampiana, e é atualizada por Hélio Oiticica em referência tanto aos desenvolvimentos internacionais como à vanguarda brasileira. Englobando as experiências de Oiticica (Núcleos, Penetráveis, Bólides, Parangolés), a antiarte conjuga linguagens, espaços e tempos dispersos, reconceituando a arte onde o objeto desintegra e sua imagem se recria. A antiarte transforma a concepção de artista: ele não é mais um criador de objetos para a contemplação, ele se torna um motivador para a criação, e a arte, uma intervenção cultural. A antiarte tem como princípio a participação advinda da subjetividade e da sua respectiva significação social. A antiarte propõe-se como investigação do cotidiano, não como diluição da arte no cotidiano.

\section{Referências}

AMARAL, A. Dos murais de Portinari aos espaços de Brasília. São Paulo: Perspectiva, 1981.

ARGAN, G. Arte Moderna. São Paulo: Companhia das Letras, 1992.

BATTCOCK, G. A nova arte. São Paulo: Perspectiva, 1986.

BENJAMIN, W. Origem do drama barroco alemão. São Paulo: Brasiliense, 1984.

BÜRGER, P. Teoria da vanguarda. Rio de Janeiro: Cosac \& Naify, 1987.

CHIPP, H. B. Teorias da Arte Moderna. São Paulo: Martins Fontes, 1993. 
DIAS, A. M. Nuno Ramos e suas torres de babel: o criador como tradutor. p. 23. In: ALENCAR, A. et. al. Tradução literária: a vertigem do próximo. Rio de Janeiro: Beco do Azougue, 2011.

ELGER, D. Dadaísmo. Alemanha: Taschen, 2005.

FABBRINI, R. A arte depois das vanguardas. Campinas: UNICAMP, 2002.

GULLAR, F. Etapas da Arte Contemporânea - do cubismo a arte neoconcreta. Rio de Janeiro: Revan, 1999.

HAUSER, A. História social da literatura e da arte. São Paulo: Mestre Jou, 1982.

HOUAISS/ KOOGAN. Enciclopédia e dicionário ilustrado. Rio de Janeiro: Seifer, 1999.

KLABIN, V. Nuno Ramos. Catálogo (apresentação). Rio de Janeiro: Centro de Artes Hélio Oiticica, 1999; São Paulo: MAM, 2000.

MOISÉS, M. Dicionário de termos literários. São Paulo: Editora Cultrix, 1997.

PRESSLER, G. K. Benjamin, Brasil: a recepção de Walter Benjamin, de 1960 a 2005: um estudo sobre a formação da intelectualidade brasileira. São Paulo: Annablume, 2006.

SELIGMANN-SILVA, M. A atualidade de Walter Benjamin e de Theodor W. Adorno. Rio de Janeiro: Civilização Brasileira, 2009.

. O local da diferença: ensaios sobre memória, arte, literatura e tradução. Rio de Janeiro: Editora 34, 2005.

STANGOS, N. Conceitos da Arte Moderna. Rio de Janeiro: Zahar, 200o.

TASSINARI, A; MAMMÌ, L. \& NAVES, R. Nuno Ramos. São Paulo: Ática, 1997.

UPJOHN, E. M. et al. História mundial da arte. Lisboa: Livraria Bertrand, 1977.

WÖLFFLIN, H. Conceitos fundamentais da História da Arte. São Paulo: Martins Fontes, 2000.

Recebido: 25/02/15

Aceito: 01/04/15

\section{CHRISTIANE DE FARIA PEREIRA ARCURI}

arcuriarte@gmail.com

Professora Adjunta de Artes Visuais e História da Arte do Instituto de Aplicação / CAp e do Instituto de Artes / IART. Autora do livro Nuno Ramos: narrativas visuais, editora Multifoco (2015). 